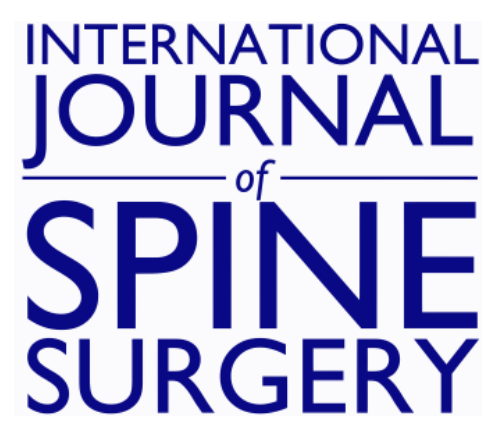

\title{
Long-Term Reliability of the Two-Segment Fusion Technique in the Treatment of Thoracolumbar Fractures Using Screws in the Fractured Vertebra
}

Francisco José Martin-Somoza, Jose Miguel Cantero Escribano and Jose Vicente

Ramírez-Villaescusa

Int J Spine Surg 2021, 15 (1) 169-178

doi: https://doi.org/10.14444/8022

http://ijssurgery.com/content/15/1/169

This information is current as of April 26, 2023.

Email Alerts Receive free email-alerts when new articles cite this article. Sign up at:

http://ijssurgery.com/alerts

The International Journal of Spine Surgery

2397 Waterbury Circle, Suite 1,

Aurora, IL 60504, Phone: +1-630-375-1432 


\title{
Long-Term Reliability of the Two-Segment Fusion Technique in the Treatment of Thoracolumbar Fractures Using Screws in the Fractured Vertebra
}

\author{
FRANCISCO JOSÉ MARTIN-SOMOZA, MD, ${ }^{1}$ JOSE MIGUEL CANTERO ESCRIBANO, MD ${ }^{2}$ JOSE \\ VICENTE RAMÍREZ-VILLAESCUSA, PHD ${ }^{3}$ \\ ${ }^{I}$ Department of Orthopaedics Surgery and Traumatology, Complejo Hospitalario Universitario de Albacete, Albacete, Spain; ${ }^{2}$ Preventive Medicine Unit, La Paz \\ University Hospital, Madrid, Spain; ${ }^{3}$ Department of Orthopaedics Surgery and Traumatology, Spine Unit, Complejo Hospitalario Universitario de Albacete, \\ Albacete, Spain
}

\begin{abstract}
Background: There is some controversy about which is the best approach, decompression technique and number of fixed levels in the surgical treatment for burst thoracolumbar fractures. Without a neurological injury, correcting thoracolumbar kyphosis and preventing mechanical failure should be the main concerns. The two-segment short fusion with screws at fractured vertebra by posterior approach was performed in 64 patients. Although a significant increase of postoperative kyphosis was observed, there were not clinical consequences, nor was there reintervention for mechanical failure.

Methods: Patients with unstable T11-L2 burst fractures and a two-level fusion including screws at the injured vertebra between 2000 and 2015 were included in the study. Demographic, clinical, and radiological variables were analyzed. Thoracolumbar, segmental, and vertebral kyphosis and anterior and posterior vertebral height were measured preoperatively, postoperatively, at one-year, and at the end of follow-up in the radiological study. The statistical analysis consisted of a descriptive analysis, and we used the $t$ test to compare the preoperative, postoperative, one-year, and end-of-follow-up radiographs to observe a thoracolumbar T10-L2 kyphosis increase. Significance level was established at $P<.05$.

Results: Fifty-four patients were included. A statistically significant increase of vertebral, segmental, and thoracolumbar kyphosis $(P<.05)$ was observed during follow-up, without clinical consequences.

Conclusions: Two-segment fusion is an effective technique and allows initial deformity kyphotic correction after thoracolumbar burst fracture. The thoracolumbar kyphosis increased during the follow-up, without pain, disability, or mechanical failure.
\end{abstract}

Level of Evidence: 2a.

Other \& Special Categories

Keywords: spinal cord injury, surgical treatment, thoracolumbar burst fractures

\section{INTRODUCTION}

Thoracolumbar vertebral fractures represent a challenging treatment, with initial instability and secondary deformity, neurological injury, or both being the main concern. The majority of the injuries are found in the thoracolumbar area (T10-L2) due to the anatomical characteristics of the region, which is a transition zone from rigid thoracic kyphosis to mobile lumbar lordosis. ${ }^{1}$

The deforming forces caused by flexion, compression, distraction, and rotation create lesions that can be identified in imaging studies. The morphological pattern of the lesion is viewed in the radiological study and is more detailed in computed tomography $(\mathrm{CT}) .^{2}$ Injuries in the posterior ligament complex, disc changes, and spinal cord injuries, which have an impact on stability and neurological function, can be evaluated more precisely through magnetic resonance (MR) imaging. ${ }^{3}$

Classification systems have been based on the mechanism and the morphological patterns of the injury through radiological study and $\mathrm{CT}^{2,4,5}$ and more recently on the status of the ligament complex by $\mathrm{MR}^{6-8}$ which allow us to establish injury severity. However, there is a great variability in treatment options, as there are few studies that establish treatment guidelines or recommendations. ${ }^{9}$ 
If a neurological lesion is present, direct decompression of neural elements by the anterior approach, indirect decompression by ligamentotaxis, direct decompression via transpedicular by the posterior approach or by the combined approach should be performed, with no significant differences regarding to the approach and type of decompression. ${ }^{10}$ When there is no neurological impairment, surgical treatment has been proposed in order to relieve pain and disability, prevent post-traumatic kyphosis and secondary deformity through correcting the vertebral height. ${ }^{11}$ However, previous studies have shown differences in the correction and maintenance of kyphosis based on injury characteristics and individual or institutional preferences. ${ }^{12}$

The pedicle screw offers a rigid fixation and has become the gold standard device that allows stabilization and reduction techniques. ${ }^{13,14}$ Shortsegment constructs provide more advantages of preserving motion segments compared with longsegment fixation. ${ }^{15}$ However, there have been failures described with the short two-segment fusion of the upper and lower segment to the fractured vertebra. ${ }^{16}$ Posterior fixation including screws at the fractured vertebra has significant biomechanical advantages over conventional short-segment fixation and could prevent mechanic failure in burst fractures. ${ }^{17,18}$

The aim of this study is to evaluate the advantages of short fusion including screws at the fracture level in type A burst fractures, as few studies have evaluated the results of two-segment short fusion of the fractured vertebra and its longterm evolution.

\section{MATERIALS AND METHODS}

\section{Study Design and Participants}

We performed a longitudinal observational retrospective study of patients with a vertebral burst fracture between 2000 and 2015 in the spinal surgery unit at our hospital. Patients with unstable types A2, A3, and A4 vertebral burst fractures located in the thoracolumbar region (T11-L2) and using short fusion with screws placed on the fractured vertebra were included in the study. Patients with pathological fractures, lesions in lumbar and thoracic locations, incorrect radiological study, or loss of follow-up by address change or death, were excluded from the study. The mean follow-up period was at least two-years.
Patients were operated on under general anesthesia and positioned in prone decubitus with the lower limbs extended in order to recover lordosis and achieve an indirect initial reduction. We took a midline posterior approach with subperiosteal dissection of the paravertebral musculature at the injured level and upper and lower segments, preserving the posterior ligamentous complex supraspinous and interspinous ligament, facet capsule and inferior facet of the superior vertebra. Pedicle preparation was performed using a straight awl and ball tip feelers. A 2-mm K-wire was placed bilaterally into pedicles in the upper, lower, and, when possible, fractured vertebra, and a 5-mm cannulated drill was used. Adequate placement was confirmed by C-arm fluoroscopy. The vertebrae above and below the fractured one were instrumented with side-connecting screws (SCS) (Colorado 2, Medtronic Sofamor/Danek, Memphis, Tennessee) or top-loading screws (TLS) (Legacy Medtronic and Expedium, De Puy Synthes, Raynham, Massachusetts) being parallel to the end plate. The fractured vertebra was instrumented with screws on both pedicles on the center of the vertebral body (A2 and A4 burst type) or toward the intact caudal vertebral body (A3 burst type), thereby checking its adequate position under image intensifier in anteroposterior (AP) and lateral (L) views. The rod was placed straight into the T10-T12 injuries and slightly bent in lordosis in the L1-L2 levels. Depending on the screw used, level of injury and grade of correction desired, final correction was achieved through combined lordosis and distraction maneuvers that contributed to improved lordosis and vertebral body height (Figures 1 and 2). Finally, 2-segment posterolateral arthrodesis using autologous cortico-cancellous bone obtained from the surgical field and posterosuperior iliac spine was performed in every case.

\section{Data Management and Follow-Up}

The minimum follow-up period was at least twoyears with radiological and clinical evaluation to check pain and neurological and functional status (returned to work).

The information was collected through the patient's history and surgical register, both in paper and digitalized. Later, it was included in a database for analysis and the data were treated confidentially. 


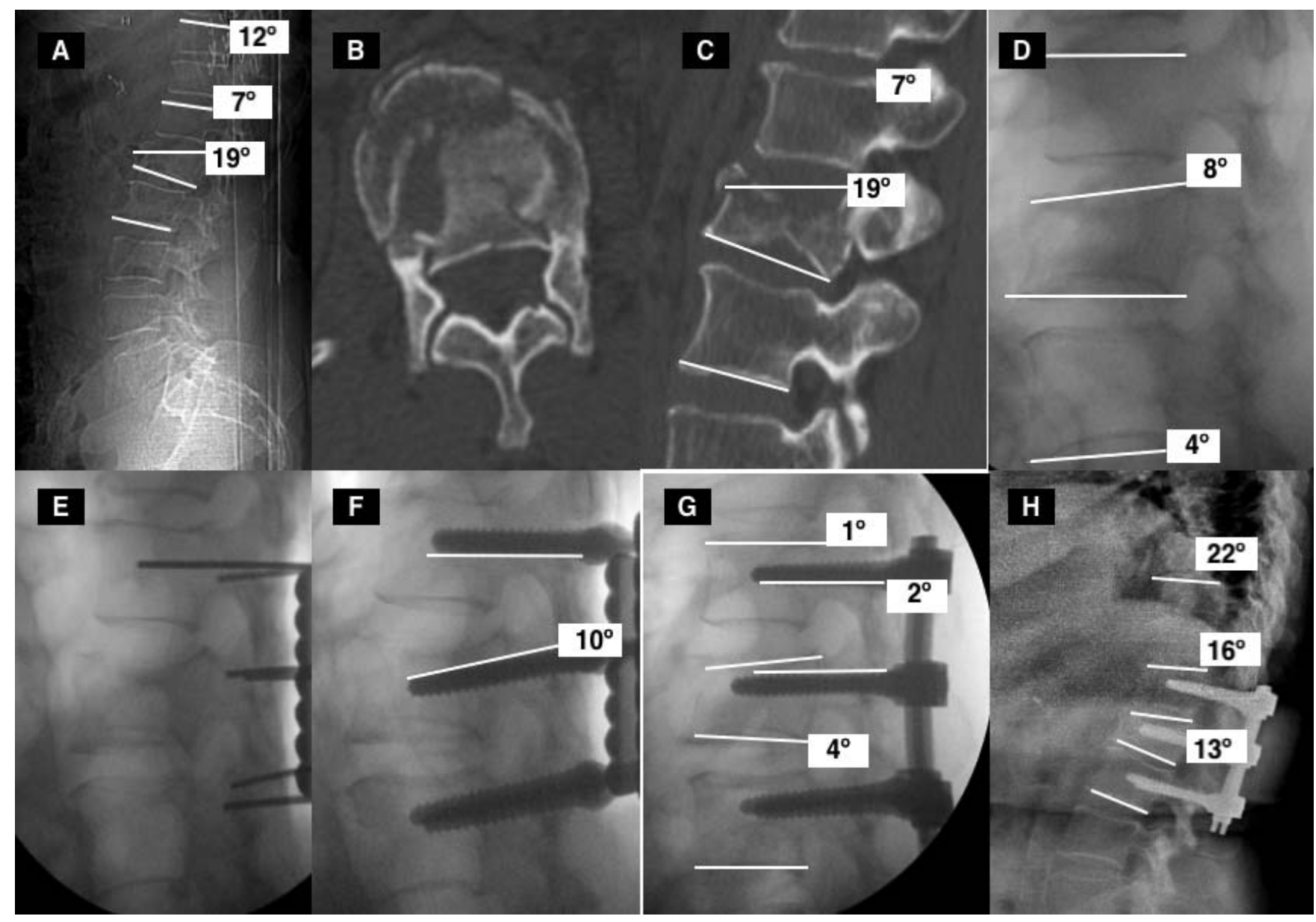

Figure 1. (A) Measurement technique of vertebral, regional and thoracolumbar kyphosis on x-ray. VK $\left(19^{\circ}\right)$ : angle based on a tangential line to the superior and inferior end plate of fractured vertebra. RK $\left(7^{\circ}\right)$ : angle based on a tangential line at the superior edge of the superior vertebra and a tangential line at the inferior edge of the inferior vertebra. TLK $\left(12^{\circ}\right)$ : angle based on a tangential line at the superior edge of $\mathrm{T} 10$ and a tangential line at the inferior edge of $\mathrm{L} 2$. (B, C) Axial and sagittal CT images that suggest a type A2 burst fracture according to AO classification. We can also perform the measurement technique on sagittal CT images. (D) Indirect initial reduction with patient positioned in prone decubitus. (VK $8^{\circ}, \mathrm{RK}^{\circ}$ ). (E) Fractured vertebra instrumented with cannulated screws on both pedicles toward the lower vertebral plate. $(\mathrm{F}, \mathrm{G})$ The placement of the slightly molded bars in lordosis and its union to the screw allowed for an adequate correction with indirect reduction of its deformity $\left(\mathrm{VK} 4^{\circ}, \mathrm{RK} 1^{\circ}\right) .(\mathrm{H}) \mathrm{X}$-ray image at the end of follow-up (8 years after surgery). A long-term progression of VK, RK, and TLK is observed (TLK $22^{\circ}$, RK $16^{\circ}$ and VK $\left.13^{\circ}\right)$. VK indicates vertebral kyphosis; RK, regional kyphosis; TLK, thoracolumbar kyphosis; CT, computed tomography.

\section{Study Variables}

The following variables were studied: (1) Demographics: age, gender, injury mechanism (casual, work related, traffic, autolysis, sportive). (2) Clinical data: neurological lesion or intact, location of the fractured vertebra, and associated lesions. (3) Intraoperative data: time elapsed until the intervention was classified as urgent $(<24$ hours), early $(24-$ 72 hours), or late ( $>72$ hours); duration; and type of instrumentation, which can be SCS or TLS and surgical complications. (4) Follow-up period. (5) Imaging studies: (a) radiology: location (T11, T12, L1, L2) and AO classification; (b) CT study: classification according to McCormack's load-sharing classification ${ }^{11}$ based on regional kyphosis, degree of communication, and fragment dispersion (score $<6$ vs $\geq 7$ ); and (c) MR study (posterior elements lesion and medullary compression).

To evaluate the degree of correction of the initial deformity and follow-up in the long term, the following measures were implemented in the radiological study, ${ }^{12}$ preoperatively, one month postoperative, and at the end of the follow-up period:

1. Postoperative vertebral kyphosis (VK) evaluated through a tangential line to the superior and inferior end plate of the fractured vertebra.

2. Regional kyphosis (RK) evaluated through a tangential line in the superior edge of the superior vertebra and a tangential line at the inferior edge of the inferior vertebra to the fractured one. 


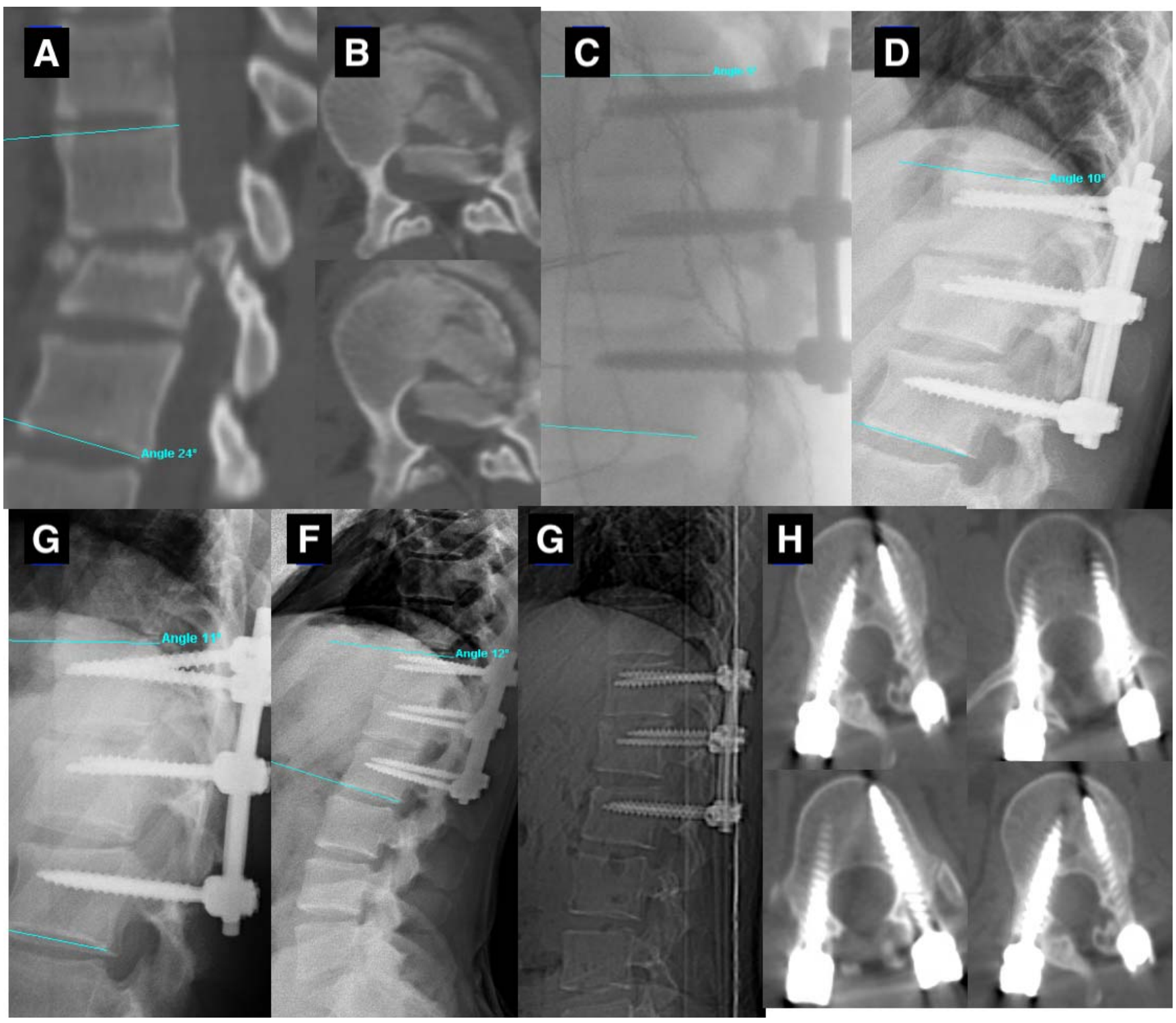

Figure 2. (A) Sagittal CT view of 25-year-old man with an L1 A3 burst fracture and preoperative T12-L2 kyphosis of $23^{\circ}$. (B) Axial CT views, where we can see a significant posterior fragment compressing the spinal cord that is neurologically intact. (C) Sagittal intraoperative view following polyaxial screw instrumentation with a TLK of $6^{\circ}$. (D-F) Sagittal view at 1 month $\left(10^{\circ}\right)$, 3 months postoperative $\left(11^{\circ}\right)$, and 5 -year follow-up $\left(12^{\circ}\right)$ with a slight increase of TLK kyphosis. (G, H) Sagittal and axial CT images. The pedicle screws were well placed at upper and lower levels, and canal clearance was observed at the L1 level. CT indicates computed tomography; TLK, thoracolumbar kyphosis.

3. Thoracolumbar kyphosis (TLK) evaluated according to Cobb's method using a tangential line traced on the superior edge of the T10 vertebra and a tangential line in the inferior edge of L2.

4. Anterior body height $(\mathrm{ABH})$ of the fractured vertebra, expressed as a percentage and obtained through the formula $\mathrm{ABH}=\mathrm{A} /$ ([superior vertebra $\mathrm{ABH}+$ inferior vertebra $\mathrm{ABH}] / 2) \times 100$.

5. Posterior body height $(\mathrm{PBH})$ of the fractured vertebra expressed as a percentage and obtained using the formula $\mathrm{PBH}=\mathrm{B} /([$ superior vertebra $\mathrm{PBH}+$ inferior vertebra $\mathrm{PBH}] / 2$ ) $\times 100$.

The measures were registered in the radiological study by an independent observer by using the linear and angular measuring tools of the image visor available in our hospital (Raim-Java).

\section{Statistical Analysis}

We performed a descriptive study of the quantitative variables as the median and interquartile 
range when they did not meet the normality condition and as a mean and SD if the variable was normal. The qualitative variables are exposed through absolute and relative frequencies.

Comparisons between quantitative variables (2 groups to compare) were carried out using the Student's $t$ test given its normal distribution, both its version for paired samples and that for independent samples for the group comparisons. To compare three or more groups, ANOVA was implemented, enforcing the Bonferroni correction.

All contrasts used were two-tailed considering a $P$ value of $5 \%$ or lower to be statistically significant. The data was analyzed through the statistical program SPSS version 23.

\section{RESULTS}

\section{Demographic Data: Patients Characteristics, Intervention, and Radiological Measures}

A total of 64 patients with burst thoracolumbar fractures (T11-L2) fulfilled the inclusion criteria, and 10 patients were excluded from the study: five patients after the surgery returned to their origin cities/countries, two could not be found with the available data, and three of them passed away.

From a total of 54 patients, $35(64.8 \%)$ were male, and $19(35.2 \%)$ were female, with a mean age of 44.07 years (SD 16.15). The most frequent production mechanism was a casual fall $(46.3 \%)$, followed by traffic accidents $(25.9 \%)$ and workrelated accidents $(18.5 \%)$. Two patients with thoracolumbar fractures related to sports were also included and three after an autolysis attempt.

Among all patients, 49 did not have neurological lesions $(90.7 \%)$, and only $5(9.3 \%)$ presented a lesion degree after the accident. Other lesions were not associated in 37 patients $(68.5 \%)$, and the remaining $17(31.5 \%)$ presented as follows: 12 $(70.6 \%)$ suffered another skeletal lesion, such as rib fractures or long bone fractures; $4(23.5 \%)$ had more than 1 vertebral lesion; and only 1 had a visceral lesion.

In terms of the time elapsed until the intervention, an urgent surgery was performed in seven patients $(13 \%)$, early in 17 patients $(31.5 \%)$, and late in 30 patients $(55.6 \%)$. The mean length of the procedure was 191.85 minutes.

The instrumentation used in the fractured vertebra and in the upper and lower vertebra consisted of
SCS in 38 patients $(70.4 \%)$ or TLS in the remaining $16(29.6 \%)$.

No surgical complications were observed in 45 patients. In nine patients $(16.7 \%)$, there were some surgical complications: one infection of surgical wounds and three needed blood transfusion due to postsurgical severe anemia. In the 5 patients with neurological preoperative neurological lesion, the same degree of lesion was maintained in the immediate postoperative period. The mean of follow-up period was 8.03 years (SD 3.75).

In the radiological study, the fractured vertebra that was observed most frequently was L1 in 32 patients $(59.3 \%)$ and T12-L2 fusion, followed by L2 in 12 patients $(22.2 \%)$ and L1-L3 and T12 in 10 patients $(18.5 \%)$ with T11-L1. From the 54 studied patients, $45(83.3 \%)$ had a preoperative radiography. In 52 patients $(96.3 \%)$, the study was extended with the performance of a thoracoabdominal CT. Through the CT study, the type of fracture was able to be stratified according to the AO classification: the most frequent fracture type was A3 with 55.6\% (30 patients), followed by A4 with $29.6 \%$ (16 patients), A2 with $13.0 \%$ (7 patients), and A1 with only 1 case collected. According to McCormack's load-sharing classification, 43 patients $(79.6 \%)$ obtained a punctuation $\leq 6$ points, and 11 patients $(20.4 \%)$ had $\geq 7$ points (Table 1$)$.

\section{Descriptive Analysis of Radiological Variables}

The RK, VK, and TLK as well as the ABH and PBH measurement results of each patient were collected in the preoperative, postoperative, oneyear and end-of-follow-up periods are shown in Table 2. Graphic representations are given in Figure 3.

\section{Comparative Analysis}

Through the Student's $t$ test for paired samples, we compared each kyphosis in every moment of the follow-up period in the preoperative and postoperative periods without analyzing subgroups.

First, we looked at the differences between kyphosis (TLK, RK, and VK) in the preoperative and postoperative, one-year, and end-of-follow-up periods. Postoperative kyphosis was also compared after one year and at the end of the tracking period (Table 2). In the same manner, we made comparisons between $\mathrm{ABH}$ loss and $\mathrm{PBH}$ loss in each of the periods (Table 2). Every comparison of the differences was significant $(P<.05)$, except for the 
Table 1. Demographic data: fractured vertebra frequency, AO classification, and load-sharing classification (LSC).

\begin{tabular}{lc}
\hline Parameter & Value \\
\hline Gender, n (\%) & \\
$\quad$ Male & $35(64.8)$ \\
Female & $19(35.2)$ \\
Age, mean (SD) & $44.07(16.1)$ \\
Level, n (\%) & $0(0)$ \\
T11 & $10(18.5)$ \\
T12 & $32(59.3)$ \\
L1 & $12(22.2)$ \\
L2 & \\
AO type, n (\%) & $1(1.9)$ \\
A1 & $7(13.0)$ \\
A2 & $30(55.6)$ \\
A3 & $16(29.6)$ \\
A4 & \\
LSC & $43(79.6)$ \\
$\quad<6$ & $11(20.4)$ \\
$\quad \geq 7$ & $49(90.7)$ \\
Neurological lesion, n (\%) & $5(9.3)$ \\
No & \\
Yes & $37(68.5)$ \\
Associated lesions, n (\%) & $17(31.5)$ \\
Yes & \\
No & $38(70.4)$ \\
Screws, n (\%) & $16(29.6)$ \\
Side-connecting screws & \\
Top-loading screws & \\
\hline
\end{tabular}

comparison of thoracolumbar kyphosis between the preoperative and end-of-follow-up periods $(P>$ $.05)$.

Second, a comparative study took place according to McCormack's load-sharing classification in which significant differences were not observed in correction loss of postoperative kyphosis in thoracolumbar, vertebral, and regional angles between both groups ( $\leq 6$ vs $\geq 7$ ) (Table 3 and Figure 4 ). Significant differences were observed $(P<.05)$ in the increase in posterior height in the fractured vertebra between the preoperative and postoperative periods, but there were no differences during the follow-up.

Third, using the same Student's $t$ test for independent samples, significant differences were observed according to the type of screw, as were differences of regional kyphosis between the postoperative and preoperative periods but not in the follow-up (Table 4 and Figure 5). No significant differences were observed according to the type of screw in the other comparisons.

Finally, ANOVA was used to compare the 3 types of lesion (burst fractures) according to the AO classification in each of the different measures (Table 5 and Figure 6). In the separate analysis of each type of fracture according to the AO, we only observed significant differences in PBH loss between the postoperative and preoperative periods. To find out which of the groups had differences between them, ANOVA was used for multiple comparisons and applying the Bonferroni correction, we observed significant differences in $\mathrm{PBH}$ loss in the measurements taken in the preoperative and postoperative periods from patients with type A4 fractures compared to patients with type A2 fractures.

\section{DISCUSSION}

The frequent location of vertebral fractures in the thoracolumbar area $\mathrm{T} 10-\mathrm{L} 2$ has been related to anatomic characteristics: the transition from a rigid thoracic to a mobile lumbar region, the change in the orientation of the facet joints (coronal facet joints of thoracic column and sagittal facet joints of lumbar column) and the change of loading bearing, from anterior loading in thoracolumbar area to the posterior loading in lumbar region. ${ }^{1}$

The choice between conservative and surgical treatment for burst fractures remains controversial. For Wood et al, ${ }^{19}$ surgical treatment for patients with stable vertebral thoracolumbar fractures with neurologically intactness does not result in any substantial benefit compared to conservative treatment with a brace. However, in patients with an initial preoperative kyphosis $>30^{\circ}$ and a vertebral body loss $>50 \%$, surgical treatment has been considered the best option to recover vertebral body height and associated kyphosis and to prevent secondary posttraumatic kyphosis, which can occasionally be severe and cause pain, disability or

Table 2. Regional, vertebral, and thoracolumbar kyphosis and anterior body height and posterior body height loss evolution during the follow-up period.

\begin{tabular}{|c|c|c|c|c|c|}
\hline & $\begin{array}{c}\text { Preoperative, } \\
\text { Mean (SD) }\end{array}$ & $\begin{array}{c}\text { Postoperative, } \\
\text { Mean (SD) }\end{array}$ & $\begin{array}{c}\text { After } 1 \text { y, } \\
\text { Mean (SD) }\end{array}$ & $\begin{array}{c}\text { Final Tracking, } \\
\text { Mean (SD) }\end{array}$ & $P$ Value \\
\hline Thoracolumbar kyphosis T10-L2, & $17.26(6.64)$ & $8.91(4.75)$ & $12.17(5.56)$ & $15.11(7.98)$ & $<.05$ (except TLK pre vs TLK follow-up) \\
\hline Regional kyphosis, ${ }^{\circ}$ & $14.98(7.14)$ & $7.50(4.45)$ & $9.83(5.25)$ & $12.11(6.81)$ & $<.05$ \\
\hline Vertebral kyphosis, ${ }^{\circ}$ & $18.85(7.03)$ & $7.57(4.10)$ & $9.44(4.30)$ & $11.80(5.46)$ & $<.05$ \\
\hline Loss in $\mathrm{ABH}, \mathrm{mm}$ & $41.69(13.24)$ & $15.47(9.81)$ & $20.05(11.32)$ & $22.29(10.38)$ & $<.05$ \\
\hline Loss in $\mathrm{PBH}, \mathrm{mm}$ & $20.45(9.09)$ & $8.35(5.21)$ & $10.98(6.53)$ & $12.31(6.50)$ & $<.05$ \\
\hline
\end{tabular}

Abbreviations: $\mathrm{ABH}$, anterior body height; $\mathrm{PBH}$, posterior body height, TLK, thoracolumbar kyphosis. 


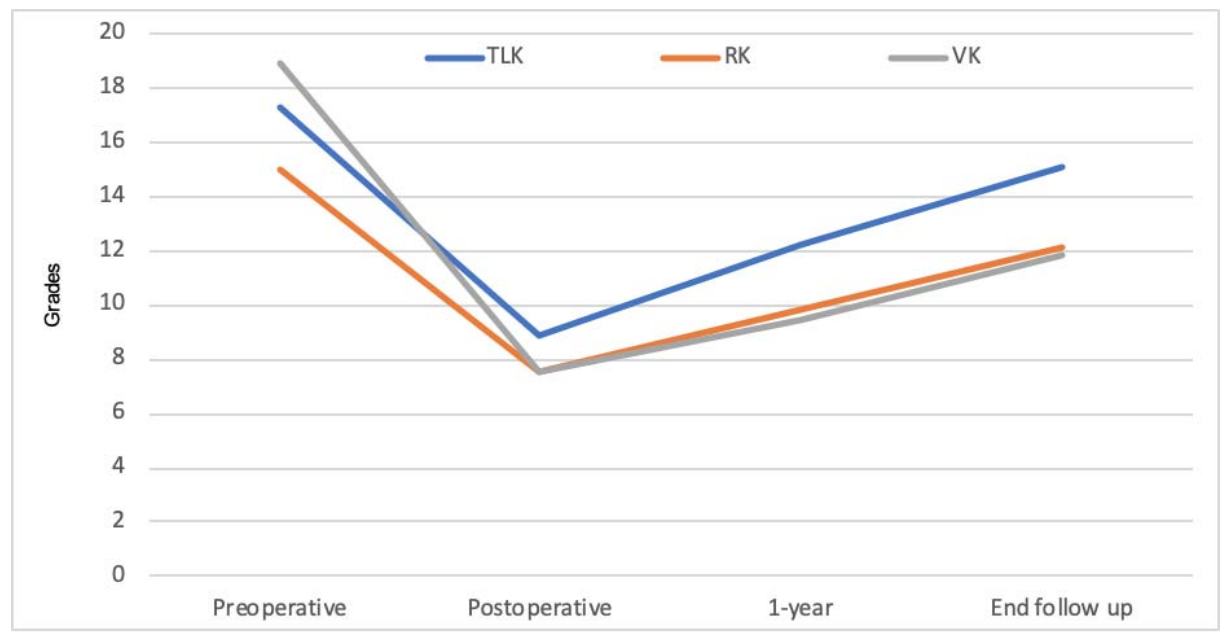

Figure 3. Evolution of the different measurements of preoperative kyphosis until the end of treatment (mean treatment 8 years).

neurological impairment, which could potentially result in surgical treatment. ${ }^{11}$

Achieving realignment and stability of the spine should be an objective when considering surgical treatment for unstable burst fractures. The anterior, posterior, or combined approach and using anterior direct or posterior transpedicular decompression have been considered. ${ }^{20}$ To preserve fusion levels and avoid complications in the proximal union related to long fixations, short fusion segments, including the immediate superior and inferior vertebra to the fractured one, have been proposed, although previous studies report mechanical failure due to them being insufficient biomechanically. ${ }^{16,21}$ Short-fusion with screws in the superior or inferior level combined with augmentation techniques at the injured vertebra with graft, tricalcium phosphate ${ }^{22}$

Table 3. Kyphosis evolution according to load-sharing classification (LSC) score.

\begin{tabular}{|c|c|c|c|c|c|c|c|c|c|c|}
\hline \multirow[b]{2}{*}{ LSC, points } & \multicolumn{3}{|c|}{ TLK (T10-L2), Mean (SD) } & \multicolumn{3}{|c|}{ SK (UV-LV), Mean (SD) } & \multicolumn{3}{|c|}{ VK, Mean (SD) } & \multirow[b]{2}{*}{$P$ Value ${ }^{\mathrm{a}}$} \\
\hline & Preoperative & Postoperative & $1 \mathrm{y}$ & Preoperative & Postoperative & $1 \mathbf{y}$ & Preoperative & Postoperative & $1 y$ & \\
\hline$<6$ & $16.56(6.46)$ & $8.58(4.28)$ & $11.65(5.02)$ & $14.00(6.47)$ & $7.09(4.31)$ & $9.35(4.92)$ & $18.23(7.26)$ & $7.32(4.36)$ & $9.30(4.27)$ & $>.05$ \\
\hline$\geq 7$ & $20.00(6.91)$ & $10.18(6.35)$ & $14.18(7.25)$ & $18.82(8.58)$ & $9.09(4.84)$ & $11.72(6.27)$ & $21.27(5.69)$ & $8.55(2.84)$ & $10.00(4.58)$ & \\
\hline
\end{tabular}

Abbreviations: LV, lower vertebra; SK, segmental kyphosis; TLK, thoracolumbar kyphosis; UV, upper vertebra; VK, vertebral kyphosis.

${ }^{\text {a }}$ Statistically significant differences between both groups of postoperative and preoperative kyphosis after one year were not observed.

Table 4. Kyphosis evolution according to instrumentation type.

\begin{tabular}{|c|c|c|c|c|c|c|c|c|c|}
\hline \multirow[b]{2}{*}{ Screws } & \multicolumn{3}{|c|}{ TLK (T10-L2), Mean (SD) } & \multicolumn{3}{|c|}{ SK (UV-LV), Mean (SD) } & \multicolumn{3}{|c|}{ VK, Mean (SD) } \\
\hline & Preoperative & Postoperative & $1 y$ & Preoperative & Postoperative & $1 \mathrm{y}$ & Preoperative & Postoperative & $1 \mathbf{y}$ \\
\hline SCS & $16.37(6.52)$ & $8.18(5.19)$ & $10.87(5.84)$ & $11.75^{*}(4.93)$ & $6.50 *(4.16)$ & $8.06(5.25)$ & $17.44(7.24)$ & $6.50(2.87)$ & $8.94(4.26)$ \\
\hline TLS & $17.63(6.74)$ & $9.21(4.59)$ & $12.71(5.43)$ & $16.34 *(7.53)$ & $7.92 *(4.55)$ & $10.57(5.13)$ & $19.45(6.94)$ & $8.03(4.48)$ & $9.66(4.35)$ \\
\hline
\end{tabular}

Abbreviations: LV, lower vertebra; SCS, side-connecting screw; SK, segmental kyphosis; TLK, thoracolumbar kyphosis; TLS, top-loading screw; UV, upper vertebra; VK, vertebral kyphosis.

*Statistically significant differences between regional kyphosis in the preoperative and postoperative comparing both groups $(P<.05)$.

Table 5. Kyphosis evolution according to the type of burst fracture.

\begin{tabular}{|c|c|c|c|c|c|c|c|c|c|}
\hline \multirow[b]{2}{*}{ AO Burst-Type } & \multicolumn{3}{|c|}{ TLK (T10-L2), Mean (SD) ${ }^{a}$} & \multicolumn{3}{|c|}{ SK $(U V-L V)$, Mean (SD) ${ }^{a}$} & \multicolumn{3}{|c|}{ VK, Mean (SD) } \\
\hline & Preoperative & Postoperative & $1 y$ & Preoperative & Postoperative & $1 y$ & Preoperative & Postoperative & $1 y$ \\
\hline A2 & $14.57(4.23)$ & $7.14(4.70)$ & $9.71(5.98)$ & $11.71(4.95)$ & $5.71(4.82)$ & $7.00(6.00)$ & $14.43(4.03)$ & $6.00(3.21)$ & $7.57(4.35)$ \\
\hline A3 & $17.50(6.97)$ & $9.60(4.65)$ & $12.50(5.08)$ & $14.46(7.30)$ & $7.83(4.51)$ & $9.60(4.98)$ & $18.57(7.02)$ & $7.30(4.82)$ & $9.47(4.93)$ \\
\hline A4 & $18.00(7.10)$ & $8.19(5.03)$ & $12.50(6.46)$ & $17.50(7.42)$ & 7.56 (3.89) & $11.37(5.32)$ & $21.63(7.33)$ & $8.63(2.60)$ & $10.00(2.80)$ \\
\hline
\end{tabular}

Abbreviations: LV, lower vertebra; SK, segmental kyphosis; TLK, thoracolumbar kyphosis; UV, upper vertebra; VK, vertebral kyphosis.

${ }^{a}$ Statistically differences were not found in regional kyphosis evolution according type of fracture in the preoperative and postoperative comparing both groups $(P>.05)$. 


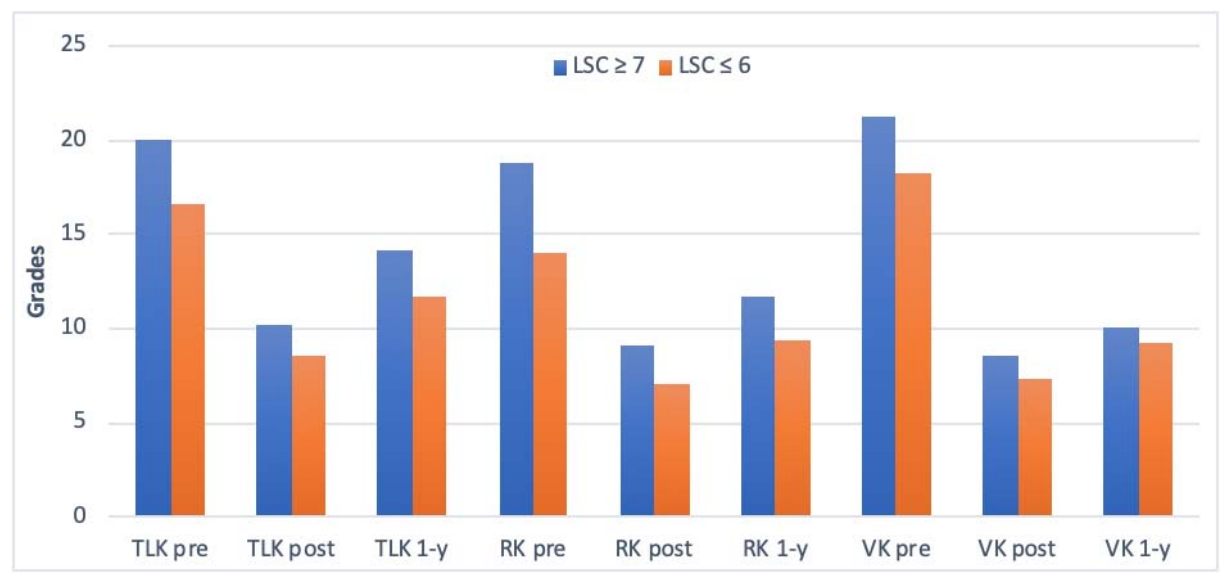

Figure 4. Representation of thoracolumbar, regional, and vertebral kyphosis evolution during the first tracking year according to LSC $\leq 6$ to $\geq 7$. LSC indicates loadsharing classification.

or polymethylmethacrylate ${ }^{23}$ have been described to prevent mechanical failure.

Short-fusion with screws placed on the fractured vertebra (six-screw construct) has been proposed to provide more mechanical stability and to prevent mechanical failure, such as breakage of implants and loss of correction. Mahar et $\mathrm{al}^{17}$ found in a cadaveric model that resistance remains unchanged only in flexion-extension and lateral bending; however, resistance to axial torsion doubles in the construct with screws on the fractured vertebra compared to the intact vertebra. Norton et al ${ }^{18}$ refer to a $31 \%$ increase in rigidity of the construct with the addition of two screws in L1 (6 screws) and an increase in the tension of the rod with the 6-screw construct in L1 and L2 compared to four-screw constructs. However, McDonnell et al, ${ }^{23}$ in another cadaveric study, do not show an increase in rigidity in short fixation screws in the fractured vertebra.
In previous studies, the validity of the study is described, analyzing in radiological studies the thoracolumbar regional and vertebral kyphosis angle as well as the loss of anterior and posterior height of the fractured vertebra with different follow-up periods. Also, the initial severity of the lesion evaluated through McCormack's load-sharing classification, ${ }^{24}$ type of burst fracture, type of pedicular instrumentation (monoaxial vs polyaxial screws), and follow-up period could influence the results.

Post-traumatic kyphosis got better in the immediate postoperative period, and a loss of kyphosis correction during the follow-up period was observed. Pellisé et $\mathrm{al}^{25}$ referred to a loss of regional and thoracolumbar kyphosis at six months of $2.90^{\circ}$ and $2.78^{\circ}$, respectively, and Gelb et $\mathrm{al}^{26}$ in ten patients with type A fractures, observed a mean loss of correction of $6.3^{\circ}$ after 12 months. Guven et al, ${ }^{27}$

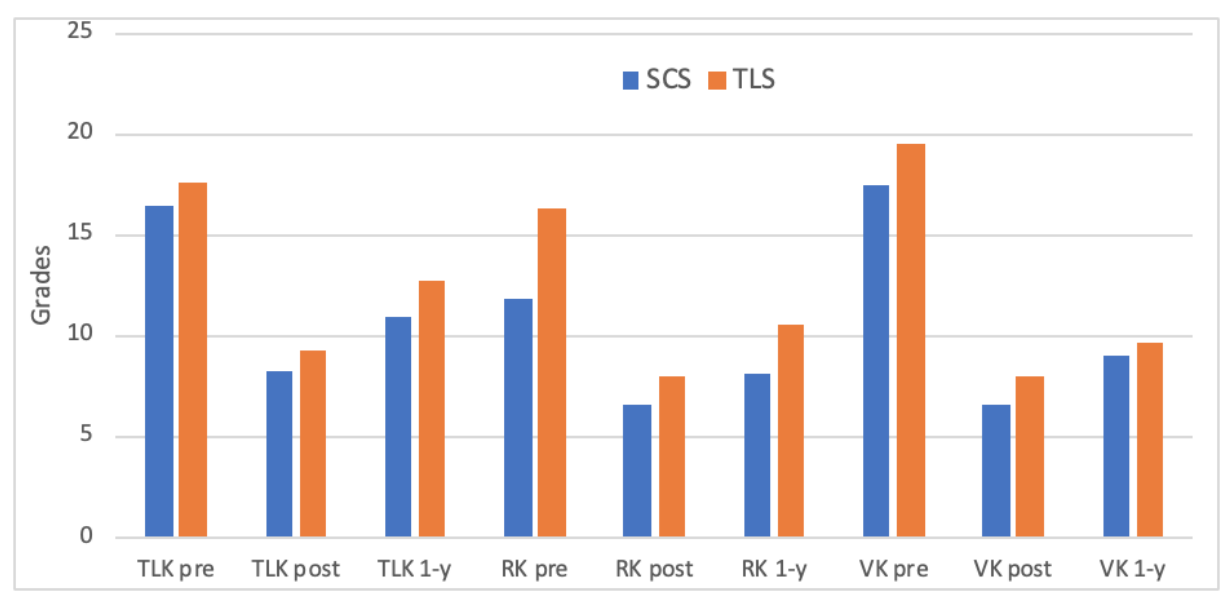

Figure 5. Regional, vertebral, and thoracolumbar kyphosis evolution depending on the type of instrumentation used (side-connecting screws or top-loading screws) during the first year of tracking time. 


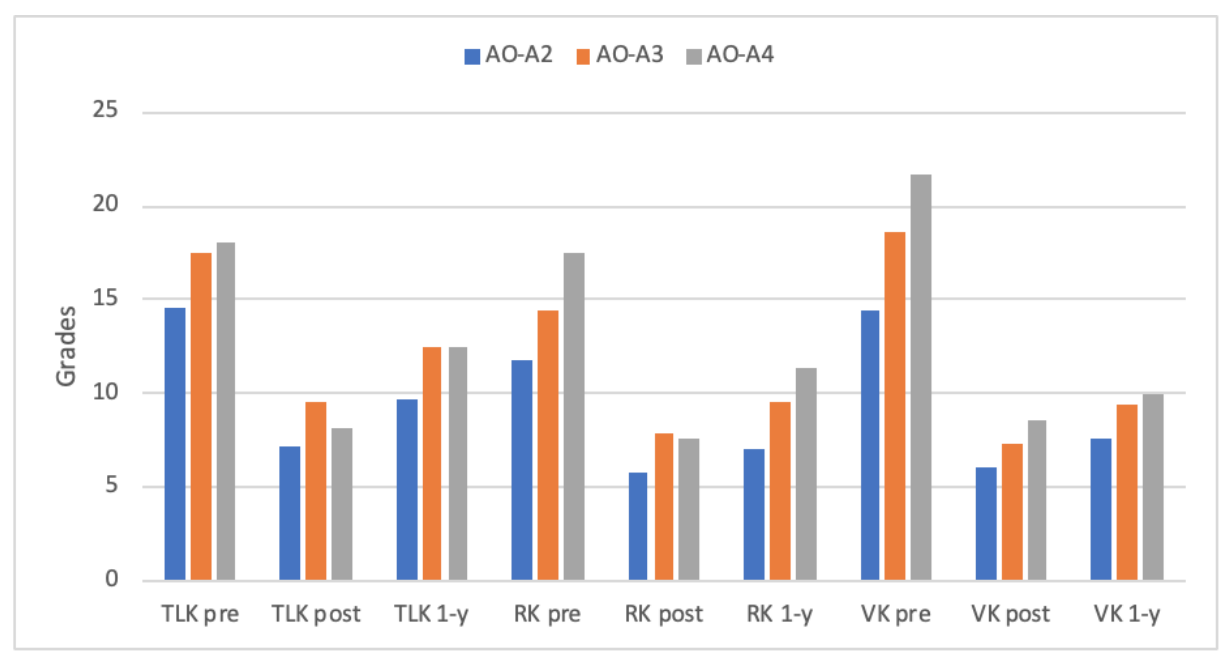

Figure 6. Thoracolumbar, vertebral, and regional kyphosis evolution depending on the type of lesion according to the AO classification (A2-A4) during the first tracking year.

with a follow-up period of 50 months, found that short fusion screws on the fractured vertebra achieve a better correction and a lower correction loss of kyphosis compared to short fixation without screws and allow saving levels compared to long fusions. The results of our study show a significant postoperative correction of thoracolumbar, vertebral, and regional kyphosis, with a slight initial loss in the first 12 months. In other studies, this loss is maintained constant during a maximum period of two years; in our study, with an eight-year follow-up period, this loss in correction of kyphosis increases slowly, with a type I post-traumatic focal sagittal deformity being well tolerated.

Patients with a load-sharing classification punctuation $\geq 7$ are exposed to a higher risk of loss in postoperative correction and during follow-up, ${ }^{28}$ even though in our study this fact has not shown significant differences. As to the type of instrumentation, other authors refer to a higher correction degree with SCS to help through indirect reduction. Regarding this point, we have not found significant differences in correction loss according to screw type ever since the intraoperative position itself maximizes lordosis so that the instrumentation type would maintain the achieved reduction.

Finally, fracture type could also be a factor affecting correction loss. The study by Farrokhi et $\mathrm{al}^{28}$ analyzed the technique's results without taking into account that the fracture type could create a potential confusion factor. ${ }^{28}$ In our study, only type A burst fractures have been evaluated, even though we have not found significant differences in correction loss according to the fracture subtype.
This study has the limitations of a retrospective study and the absence of MRI in every single case, which has prevented evaluating the lesion of the posterior ligamentous complex. The advantages of our study were that every patient was intervened by the same surgeons through the same surgical technique. Also, type A burst fractures are evaluated in a homogeneous manner versus the heterogeneity of other studies that compare different types of lesions, in addition to a long follow-up that has allowed monitoring changes in the long term.

The short fixation technique with screws on the fractured vertebra allows the reduction and maintaining of kyphosis in the immediate postoperative period. If a progressive loss during follow-up is observed, it is well tolerated by the patient without clinical repercussion or need for revisions.

\section{ACKNOWLEDGMENTS}

Thanks to Ana Ramirez-Villaescusa, Alejandro García-Alonso, and Ana Ramirez-Martinez for their support.

\section{REFERENCES}

1. Alpantaki K, Bano A, Pasku D, et al. Thoracolumbar burst fractures: a systematic review of management. Orthopedics. 2010;33(6):422-429.

2. Magerl F, Aebi M, Gertzbein et al. A comprehensive classification of thoracic and lumbar injuries. Eur Spine $J$. 1994;3(4):184-201.

3. Vaccaro AR, Rihn JA, Saravanja D, et al. Injury of the posterior ligamentous complex of the thoracolumbar spine: a prospective evaluation of the diagnostic accuracy of magnetic 
resonance imaging. Spine (Phila Pa 1976). 2009;34(23):E841E847.

4. Denis F. The three column spine and its significance in the classification of acute thoracolumbar spinal injuries. Spine (Phila Pa 1976). 1983;8(8):817-831.

5. Panjabi MM, Oxland TR, Kifune M, Arand M, Wen L, Chen A. Validity of the three-column theory of thoracolumbar fractures. Spine (Phila Pa 1976). 1995;20(10):1122-1127.

6. Vaccaro AR, Lehman RA, Hurlbert RJ, et al. A new classification of thoracolumbar injuries: the importance of injury morphology, the integrity of the posterior ligamentous complex, and neurologic status. Spine (Phila Pa 1976). 2005;30(20):2325-2333.

7. Vaccaro AR, Oner C, Kepler CK, et al. AO spine thoracolumbar spine injury classification system: fracture description, neurological status, and key modifiers. Spine (Phila Pa 1976). 2013;38(23):2028-2037.

8. Reinhold M, Audigé L, Schnake KJ, Bellabarba C, Dai LY, Oner FC. AO spine injury classification system: a revision proposal for the thoracic and lumbar spine. Eur Spine J. 2013;22(10):2184-2201.

9. Vaccaro AR, Lim MR, Hurlbert RJ, et al. Surgical decision making for unstable thoracolumbar spine injuries: results of a consensus panel review by the Spine Trauma Study Group. J Spinal Disord Tech. 2006;19(1):1-10.

10. Oner FC, Wood KB, Smith JS, et al. Therapeutic decision making in thoracolumbar spine trauma. Spine (Phila Pa 1976). 2010;35(suppl 21):S235-S244.

11. Vaccaro AR, Silber JS. Post-traumatic spinal deformity. Spine (Phila Pa 1976). 200;26(suppl 24):S111-S118.

12. Verlaan JJ, Diekerhof $\mathrm{CH}$, Buskens E, et al. Surgical treatment of traumatic fractures of the thoracic and lumbar spine: a systematic review of the literature on techniques, complications, and outcome. Spine (Phila Pa 1976). 2004;29(7):803-814.

13. Zou D, Yoo JU, Edwards WT, et al. Mechanics of anatomic reduction of thoracolumbar burst fractures. Comparison of distraction versus distraction plus lordosis, in the anatomic reduction of the thoracolumbar burst fracture. Spine (Phila Pa 1976). 1993;18(2):195-203.

14. Oda T, Panjabi MM, Kato Y. The effects of pedicle screw adjustments on the anatomical reduction of thoracolumbar burst fractures. Eur Spine J. 2001;10(6):505-511.

15. Vialle LR, Vialle E, Guasque J, Rocha LG. Short or long posterior fusion: determining the extent of fixation. In: AOSpine Master Series. Vol. 6. New York, NY: Thieme; 2016:85-96.

16. McLain RF, Sparling E, Benson DR. Early failure of short-segment pedicle instrumentation for thoracolumbar fractures. A preliminary report. $J$ Bone Jt Surg Am. 1993;75(2):162-167.

17. Mahar A, Kim C, Wedemeyer M, et al. Short-segment fixation of lumbar burst fractures using pedicle fixation at the level of the fracture. Spine (Phila Pa 1976). 2007;32(14):15031507.

18. Norton RP, Milne EL, Kaimrajh DN, et al. Biomechanical analysis of four- versus six-screw constructs for shortsegment pedicle screw and rod instrumentation of unstable thoracolumbar fractures. Spine (Phila Pa 1976). 2014;14(8):1734-1739.

19. Wood K, Buttermann G, Mehbod, A et al. Operative compared with nonoperative treatment of a thoracolumbar burst fracture without neurological deficit: a prospective, randomized study. J Bone Jt Surg Am. 2003;85(5):773-781.

20. Sasani M, Özer AF. Single-stage posterior corpectomy and expandable cage placement for treatment of thoracic or lumbar burst fractures. Spine (Phila Pa 1976). 2009;34(1):E33E40.

21. Tezeren G, Kuru I. Posterior fixation of thoracolumbar burst fracture short-segment pedicle fixation versus longsegment instrumentation. J Spinal Disord Tech. 2005;18(6):485-488.

22. Marco RA, Meyer BC, Kushwaha VP. Thoracolumbar burst fractures treated with posterior decompression and pedicle screw instrumentation supplemented with balloonassisted vertebroplasty and calcium phosphate reconstruction. J Bone Jt Surg Am. 2010;92(1):67-76.

23. McDonnell M, Shah KN, Paller DJ, et al. Biomechanical analysis of pedicle screw fixation for thoracolumbar burst fractures. Orthopedics. 2016;39(3):e514-e518.

24. McCormack T, Karaikovic E, Gaines RW. The load sharing classification of spine fractures. Spine (Phila Pa 1976). 1994;19(15):1741-1744.

25. Pellise F, Barastegui D, Hernandez-Fernandez A, et al. Viability and long-term survival of short-segment posterior fixation in thoracolumbar burst fractures. Spine (Phila $\mathrm{Pa}$ 1976). 2015;15(8):1796-1803.

26. Gelb D, Ludwig S, Karp JE, et al. Successful treatment of thoracolumbar fractures with short-segment pedicle instrumentation. Clin Spine Surg. 2010;23(5):293-301.

27. Guven O, Kocaoglu B, Bezer M, et al. The use of screw at the fracture level in the treatment of thoracolumbar burst fractures. J Spinal Disord Tech. 2009;22(6):417-421.

28. Farrokhi MR, Razmkon A, Maghami Z, et al. Inclusion of the fracture level in short segment fixation of thoracolumbar fractures. Eur Spine J. 2010;19(10):1651-6.

Disclosures and COI: The authors declare no conflict of interest.

Corresponding Author: Francisco José Martin Somoza, MD, Complejo Hospitalario Universitario De Albacete, Orthopedics and Traumatology Department, Hermanos Falcó 37, 02006 Albacete, Spain. Phone: +34677361737; Fax: +34967597290; Email: franmsomoza@gmail.com.

Published 26 February 2021

This manuscript is generously published free of charge by ISASS, the International Society for the Advancement of Spine Surgery. Copyright (C) 2021 ISASS. To see more or order reprints or permissions, see http://ijssurgery.com. 